\title{
Aging reduces the primary humoral response and the in vitro cytokine production in mice
}

P.U. Simioni,

E.H. Costa and W.M.S.C. Tamashiro
Departamento de Microbiologia e Imunologia, Instituto de Biologia, Universidade Estadual de Campinas, Campinas, SP, Brasil

\author{
Correspondence \\ W.M.S.C. Tamashiro \\ Departamento de Microbiologia e \\ Imunologia \\ Instituto de Biologia, UNICAMP \\ Rua Monteiro Lobato, 255 \\ 13083-862 Campinas, SP \\ Brasil \\ Fax: +55-19-3521-6276 \\ E-mail: wirlatam@unicamp.br \\ Research supported by FAPESP \\ (No. 94/6277-1 and 05/51520-8). \\ P.U. Simioni and E.H. Costa were \\ the recipients of FAPESP fellowships \\ (Nos. 94/4219-4 and 94/4215-9, \\ respectively). \\ $\ldots \ldots \ldots \ldots \ldots \ldots$
}

Received August 28, 2006

Accepted May 21, 2007

\begin{abstract}
Aging is accompanied by a decrease in several physiological functions that make older individuals less responsive to environmental challenges. In the present study, we analyzed the immune response of female BALB/c mice $(\mathrm{N}=6)$ of different ages (from 2 to 96 weeks) and identified significant age-related alterations. Immunization with hapten-protein (trinitrophenyl-bovine serum albumin) conjugates resulted in lower antibody levels in the primary and secondary responses of old mice (72 weeks old). Moreover, young mice $(2,16$, and 32 weeks old) maintained specific antibodies in their sera for longer periods after primary immunization than did old mice. However, a secondary challenge efficiently induced memory in old mice, as shown by the increased antibody levels in their sera. The number of $\mathrm{CD}^{+}{ }^{+}$and $\mathrm{CD} 8^{+} \mathrm{T}$ cells in the spleen increased until 8 weeks of age but there was no change in the $\mathrm{CD} 4^{+} / \mathrm{CD}^{+}$ratio with aging. Splenic $\mathrm{T}$ cells from old mice that had or had not been immunized were less responsive to concanavalin-A and showed reduced cytokine production compared to young mice (IL-2: 57-127 vs 367-1104 pg/mL, IFN$\gamma:$ 2344-12,836 vs 752-23,106 pg/mL and IL-10: 393-2172 vs 105$2869 \mathrm{pg} / \mathrm{mL}$ in old and young mice, respectively). These data suggest that there are significant changes in the organization of the immune system throughout life. However, the relevance of these alterations for the functioning of the immune system is unknown.
\end{abstract}

\section{Introduction}

The aging process is associated with a variety of changes in the physiology of an organism and, although no universally recognized senescent marker has been identified (1-3), various promising candidates have been suggested, including total serum glutathione concentration as an accessible index
Key words

- Aging

- Cytokines

- Antibody

- Proliferation

- T cell response

- T cell subsets $\ldots \ldots \ldots \ldots \ldots \ldots$

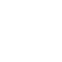


$\mathrm{T}$ cell responsiveness to a variety of antigens, a fact that may contribute to the significant increase in the incidence of infectious diseases observed in older individuals (5-7).

The aging process is marked by functional impairment of the antibody response in both mice and humans (6). The aged immune system usually generates antibodies with a lower avidity compared to the system of younger individuals $(5,8)$. The capacity to mount a primary humoral response is also reduced during aging (8-12). In aged mice, bone marrow functions as a late antibody production site, although the numbers of antibody-forming cells are reduced compared to younger animals, a fact that is related to the reduced primary response (13). The aging process also affects the repertoire and diversity of B cells (14).

$\mathrm{T}$ cell-mediated immunity is a multifactorial phenomenon affecting $\mathrm{T}$ cell subset composition as well as lymphocyte proliferation and cytokine production along the pathway of T cell activation. However, it has been shown that aging decreases T cell proliferation and IL-2 production in both humans and experimental models (for reviews, see Refs. 7 and 15), although a few discrepant experiments showed no change or an increase in IL-2 production in response to a mitogen in old subjects (for reviews, see Ref. 7). Some reports have shown that leukocytes of aged mice present an increase in IL-4 secretion as well as a decrease of IL-2 production, thus indicating a shift to the $\mathrm{TH} 2$ responses due to age (for reviews, see Refs. 15 and 16-19).

Although aging seems to affect the proportions of peripheral CD4 and CD8 T cells as well as $\mathrm{T}$ cell functions in mice and humans, literature data concerning these matters are conflicting $(17,20-25)$. Some reports have shown a decline in CD8 $\mathrm{T}$ cells in spleen, but not in gut-associated lymphoid tissue in humans, while no alteration in CD4 $\mathrm{T}$ cells was found (24). However, Callahan and collaborators (20) reported a decrease in the $\mathrm{CD} 4 / \mathrm{CD} 8$ ratio in mice as they aged, reflecting a significant decrease in $\mathrm{CD} 4 \mathrm{~T}$ cell numbers and only a slight decrease in CD8 T cells (20).

Although the knowledge of T cell function and activation has greatly improved on the last decade, the question of whether differences between young and old individuals are due to altered $\mathrm{T}$ cell subset composition has not been properly answered. In addition, many studies on aging are carried out using specific points in mice development, arbitrarily defined as young or old. Since many factors may be involved, we organized a systematic study of the effects of aging on the immune system of rodents, simultaneously considering the main aspects of the adaptive immune response of both naive and immunized $\mathrm{BALB} / \mathrm{c}$ mice at various stages of postnatal development, including serum antibody levels, concanavalin-A (Con-A)induced $\mathrm{T}$ cell proliferation, production of cytokines by mitogen-activated spleen cells, and profile of naive $\mathrm{CD} 4^{+}$and $\mathrm{CD} 8^{+} \mathrm{T}$ cells.

\section{Material and Methods}

\section{Mice}

Two- or four-week-old female BALB/c mice were supplied by the Multi-Institutional Center for Biological Investigation (CEMIB) of the State University of Campinas, Campinas, Brazil. The mice were housed under pathogen-free conditions and received a diet of autoclaved food and water. The University Committee for Ethics in Animal Experimentation approved this study (No. 912-1).

\section{Reagents}

Type $\mathrm{V}$ bovine serum albumin (BSA), type VI ovalbumin (OVA) and 2,4,6-trinitrobenzenesulfonic acid were purchased from 
Sigma (St. Louis, MO, USA). TrinitrophenylBSA (TNP-BSA) and TNP-OVA were prepared as described elsewhere $(26,27$, respectively). mrIL-4 and mrIFN- $\gamma$ were purchased from Genzyme (Cambridge, MA, USA) and Genentech Inc. (South San Francisco, CA, USA), respectively. The monoclonal antiCD4 and anti-CD8 antibodies (mAbs) conjugated with fluorescein isothiocyanate (FITC) and anti-CD3 conjugated with phycoerythrin were purchased from PharMingen (San Diego, CA, USA).

\section{Immunization}

Mice were immunized intraperitoneally with $100 \mu \mathrm{g}$ TNP-OVA conjugate and Freund's complete adjuvant (FCA) $(1: 1, \mathrm{v} /$ v). On day 28 , some of the mice had this immunization boosted with an additional $100 \mu \mathrm{g}$ TNP-OVA diluted in $0.15 \mathrm{M}$ saline solution. The mice were bled monthly and the sera used for measuring antibody production. Zero, 14, 28, and 60 days after the first immunization, mice were sacrificed in a $\mathrm{CO}_{2}$ chamber and their spleens were isolated aseptically.

\section{Antibody assays}

Titers of TNP-BSA and TNP antibodies were determined by standard ELISA using an automatic ELISA reader (Multiskan II, MS, Labsystem, Helsinki, Finland). Microtiter plates (Falcon, BD Bioscience, Franklin Lakes, NJ, USA) were coated with either TNP-BSA or TNP-OVA by adding $50 \mu \mathrm{L}$ protein solution $(10 \mu \mathrm{g} / \mathrm{mL}$ in carbonate/ bicarbonate buffer, $\mathrm{pH}$ 9.6) to each well, and incubating the plates overnight at $4^{\circ} \mathrm{C}$. The wells were washed with phosphate-buffered saline (PBS) solution containing $0.05 \%$ Tween 20 and then blocked with $5 \%(\mathrm{w} / \mathrm{v})$ skim milk in PBS for $1 \mathrm{~h}$ at $37^{\circ} \mathrm{C}$. After washing with PBS containing $0.05 \%$ Tween 20 , the plates were incubated for $1 \mathrm{~h}$ at $37^{\circ} \mathrm{C}$ with mouse anti-serum diluted in PBS from
$1: 100$ to $1: 12,800$, washed again and incubated with rabbit anti-mouse immunoglobulin antibodies $(275 \mathrm{ng} / \mathrm{mL})$ for $1 \mathrm{~h}$ at $37^{\circ} \mathrm{C}$. The plates were washed again, and $50 \mu \mathrm{L}$ of a freshly prepared substrate chromogen $\left(0.03 \% \mathrm{H}_{2} \mathrm{O}_{2}\right.$ and $0.04 \%$ ortho-phenylenediamine in $50 \mathrm{mM}$ citric acid/di-sodium hydrogen phosphate buffer, $\mathrm{pH}$ 5.5) was added to each well. After $30 \mathrm{~min}$ in the dark, the reaction was stopped by adding $25 \mu \mathrm{L} 4 \mathrm{~N}$ $\mathrm{H}_{2} \mathrm{SO}_{4}$ to the wells, and absorbance was read at $492 \mathrm{~nm}$. ELISA scores were computed for individual mice by summing the absorbances of progressively more diluted serum. Data are reported as means \pm SEM for 5 mice in each group (28).

\section{Spleen cell culture}

The spleens from individual mice were aseptically collected and the cells were homogenized with a grinder in RPMI 1640 medium (Sigma) supplemented with 10\% fetal calf serum (FCS; Nutricell; São Paulo, SP, Brazil), sodium bicarbonate (2 g/L), HEPES buffer (2 g/L) and 2-mercaptoethanol $(2 \mu \mathrm{L} / \mathrm{L})$. After incubation for 4 min with lysis solution $\left(\mathrm{NH}_{4} \mathrm{Cl}, \mathrm{KHCO}_{3}\right.$, and EDTA) at room temperature, cells were pelleted at $200 \mathrm{~g}$ for $10 \mathrm{~min}$. The cells were then suspended in RPMI 1640 with 10\% FCS and assayed for proliferation, cytokine production and phenotype determination.

\section{Mitogenic response}

Proliferation assays were performed in 96-well tissue culture plates (Corning Co., Cambridge, MA, USA). Spleen cells were seeded at a density of $2 \times 10^{5} /$ well in RPMI 1640 supplemented with $10 \%$ FCS and cultured in the presence of Con-A $(2.5 \mu \mathrm{g} / \mathrm{mL}$, Sigma) in a $5 \% \mathrm{CO}_{2}$ atmosphere at $37^{\circ} \mathrm{C}$. Three days later, $10 \mu \mathrm{L}$ of a $5 \mathrm{mg} / \mathrm{mL} 3-[4,5-$ dimethyltiazol-2-yl] diphenyltetrazolium bromide solution (Sigma) was added to each culture, and plates were incubated for an 
additional $4 \mathrm{~h}$. To dissolve formazan crystals, $10 \mu \mathrm{L} 10 \%$ sodium dodecyl sulfate (Bio-Rad Laboratories, Inc., Hercules, CA, USA) was added to each well, and plates were incubated overnight at $37^{\circ} \mathrm{C}$. Absorbance was determined with an automatic ELISA reader (Multiskan II), at $540 \mathrm{~nm}$ and used to indicate $\mathrm{T}$ cell proliferation (28).

\section{Cytokine measurement}

For cytokine determination, cell suspensions were placed in 24-well tissue culture plates (Corning) at a density of $2.5 \times 10^{6}$ cells/well in RPMI-10\% FCS and stimulated with $2.5 \mu \mathrm{g} / \mathrm{mL}$ Con-A. After $72 \mathrm{~h}$ of incubation, the culture supernatants were collected, and ELISA was used to quantify cytokine levels. IL-2 and IL-10 measurements were carried out with commercial kits according to manufacturer instructions (Mouse Interleukin-2 ELISA kit (Intertest-2X) from Genzyme Immunologicals, Cambridge, MA, USA and Mouse Interleukin-10 ELISA kit from Endogen Pierce Biotechnology, Rockford, IL, USA). The assays for the detection of IL-4 and IFN- $\gamma$ used pairs of specific mAbs prepared in our laboratory, and were carried out as described elsewhere (29).

\section{Flow cytometry analysis}

Anti-CD4/FITC, anti-CD8/FITC and anti-CD3/phycoerythrin were used to stain spleen cells obtained from naive mice of different ages, as described elsewhere (28). Briefly, mAbs or isotype controls were added to polystyrene tubes containing $1 \times 10^{6}$ spleen cells, which were incubated at $4^{\circ} \mathrm{C}$ for 40 min. Cells were washed with PBS and suspended with PBS containing 1\% formaldehyde. Preparations were analyzed with a FACScan flow cytometer using Cell Quest software (BD Bioscience). For subset analysis, the populations with forward and side light scatter characteristics of lymphocytes were gated initially.

\section{Statistical analysis}

The two-tailed Student $t$-test was used to compare the different experimental groups, with the level of significance set at $\mathrm{P}<0.05$.

\section{Results}

\section{In vivo primary and secondary antibody responses in BALB/c mice}

Primary antibody responses were determined in mice aged 2, 16, 32, and 72 weeks. All mice were injected intramuscularly with one dose of TNP-BSA emulsified in 50\% FCA. ELISA was used to monitor increases of specific antibodies in the sera, which were collected weekly from all groups of mice until 48 weeks after the challenge or natural death. The results of these experiments are presented in Figure 1. Maximum levels of antibodies against TNP-BSA were observed about 4 to 8 weeks after antigen administration. Mice immunized at 16 weeks of age (adults) presented the highest antibody levels. The oldest mice (72 weeks at immunization) presented the greatest reduction in the levels of antibodies against TNP-BSA conjugate (panel A). Similarly, the production of anti-TNP antibodies was more elevated in young than in old mice (panel B).

The secondary humoral immune response was evaluated in the sera of mice that had received a booster of TNP-BSA in the absence of an adjuvant 28 days after the primary challenge with the antigen. All groups of mice showed a secondary response against TNP-BSA, as revealed by higher ELISA scores. These scores peaked 4 weeks after the second challenge (Figure 1, panel C). Mice immunized at 72 weeks of age presented the lowest levels of secondary response. Once again, sera from the mice initially immunized at 16 weeks of age maintained the highest scores for antibodies against TNP-BSA (panel C). The secondary antibody response against TNP followed the 
same pattern as that observed for the protein-hapten complex (panel D).

\section{Proliferative response and cytokine production}

Spleens were collected from BALB/c mice of different ages at day 0 (naive), 14 , 28 (primary response), or 60 (secondary response) after immunization with TNP-BSA. Cells were stimulated with Con-A and the proliferative response was measured $72 \mathrm{~h}$ later by a colorimetric assay. Figure 2 summarizes the results obtained in these experiments. Spleen cells from naive or immu- nized mice proliferated significantly in response to Con-A. Spleen cells from young mice ( 2 and 4 weeks of age) immunized with TNP-BSA were more responsive to Con-A than cells from naive mice $(\mathrm{P}<0.05)$. In contrast, cells from old mice (48 and 72 weeks of age) collected at 28 and 60 days after immunization were the least responsive to Con-A stimulation $(\mathrm{P}<0.05)$. Cells from adult mice (16 and 32 weeks old) displayed a similar proliferative response to Con-A, regardless of treatment.

The secretion of TH1 (IL-2 and IFN- $\gamma$ ) and TH2 (IL-4 and IL-10) cytokines was meas-

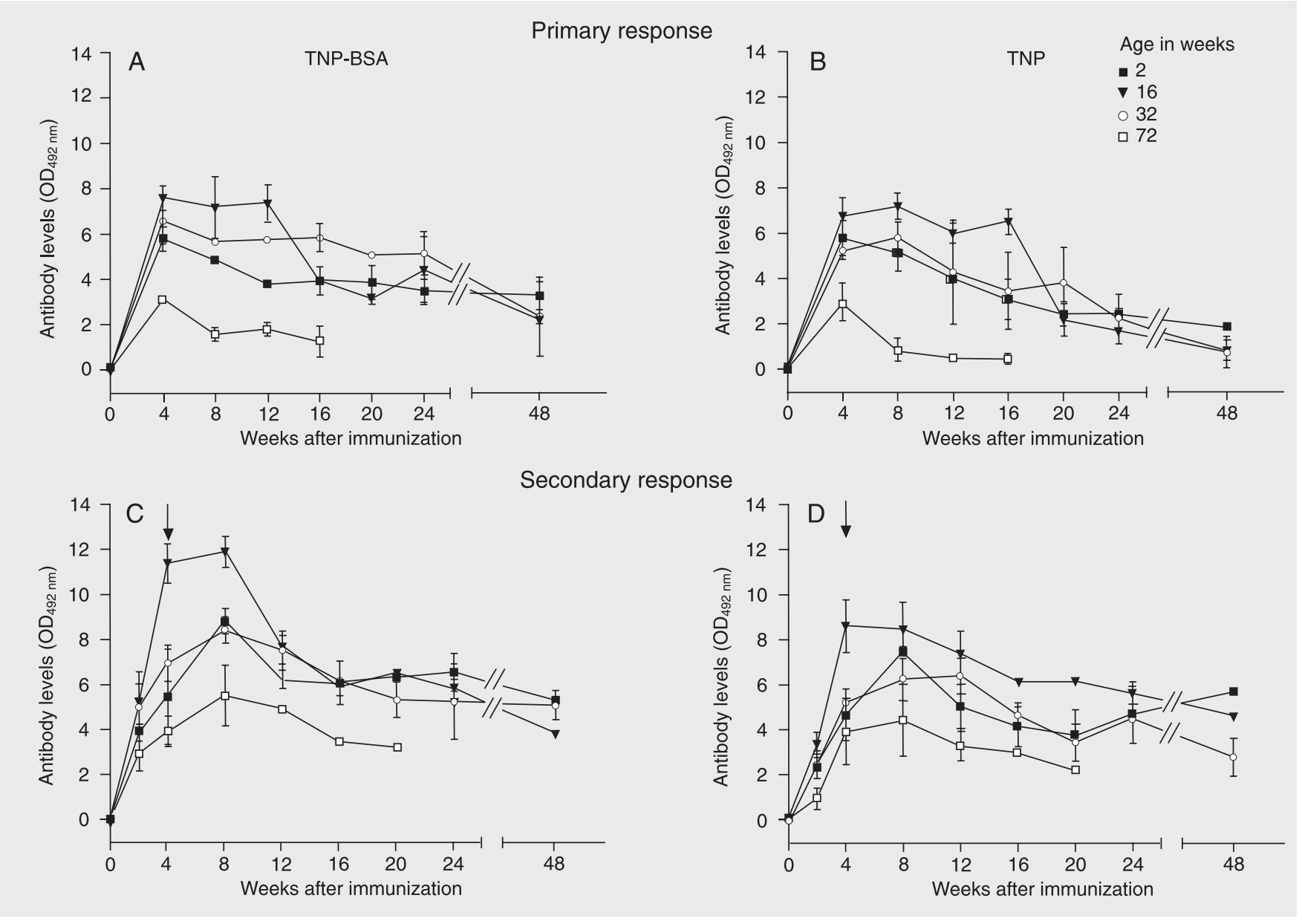

Figure 1. Effect of aging on antibody levels in the sera of BALB/c mice. Sera were collected monthly for 12 months or until natural death from mice (N $=5$ ) of different ages, which were immunized with one (primary response; panels A and B) or two (secondary response; panels $C$ and D) doses of trinitrophenyl-bovine serum albumin (TNP-BSA). The arrows in panels $C$ and $D$ indicate the administration of the challenge dose. Antibody titers to TNP-BSA and TNP were determined by ELISA using TNP-BSA (panels A and C) or TNP-ovalbumin (panels B and D) as coating proteins, respectively. Antibody levels are reported as the mean \pm SEM of individual running sums of absorbance readings for serum dilutions of 1:100 to 1:12,800. 
Figure 2. Influence of age on $T$ cell proliferation. Spleen cell of BALB/c mice of different ages were collected $0,14,28$ or 60 days after immunization with trinitrophenyl-bovine serum albumin and cultured for $72 \mathrm{~h}$ in the presence of concanavalin-A $(2.5 \mu \mathrm{g} / \mathrm{mL})$. Proliferation was measured by the diphenyltetrazolium bromide-staining assay, in six replicates, with spleen cells pooled from 3 to 6 mice. The baseline represents $T$ cells cultured in the absence of concanavalin-A. Data are reported as mean \pm SEM absorbance at $540 \mathrm{~nm}$ and are representative of three independent experiments. ${ }^{*} P<0.05$ compared to their respective naive group (Student $t$-test).

Figure 3. Cytokine levels in the supernatant of concanavalin-Astimulated spleen cells from aged mice. Mice were immunized with trinitrophenyl-bovine serum albumin at different ages and their spleens were collected $0,14,28$, or 60 days after antigen injection. Cell suspensions of each group of mice were pooled and seeded in six replicates and then cultured in the presence of concanavalin-A (2.5 $\mu \mathrm{g} / \mathrm{mL}$ ) for $72 \mathrm{~h}$. The levels of interleukin-2 (IL-2; panel A), interferon- $\gamma$ (IFN- $\gamma$; panel B), IL-4 (panel C), and IL-10 (panel D) were measured by ELISA in the pooled culture supernatants. Data are reported as mean \pm SEM cytokine concentrations and are representative of two independent experiments. ${ }^{*} \mathrm{P}<$ 0.05 compared to their respective naive group (Student $t$-test). ured in the supernatants of the Con-A-stimulated spleen cells (Figure 3). IL-2 secretion was detected in the supernatants of Con-Astimulated cells of neonate (2 weeks old), young (16 weeks old) and adult (32 weeks old) mice, but not in the supernatants of the oldest animals (Figure 3A). Con-A-stimulated IFN- $\gamma$ secretion increased in the supernatants of cells obtained from immunized mice as a function of time of immunization and animal age up to 32 weeks of age, decreasing thereafter in the oldest group (Figure 3B).
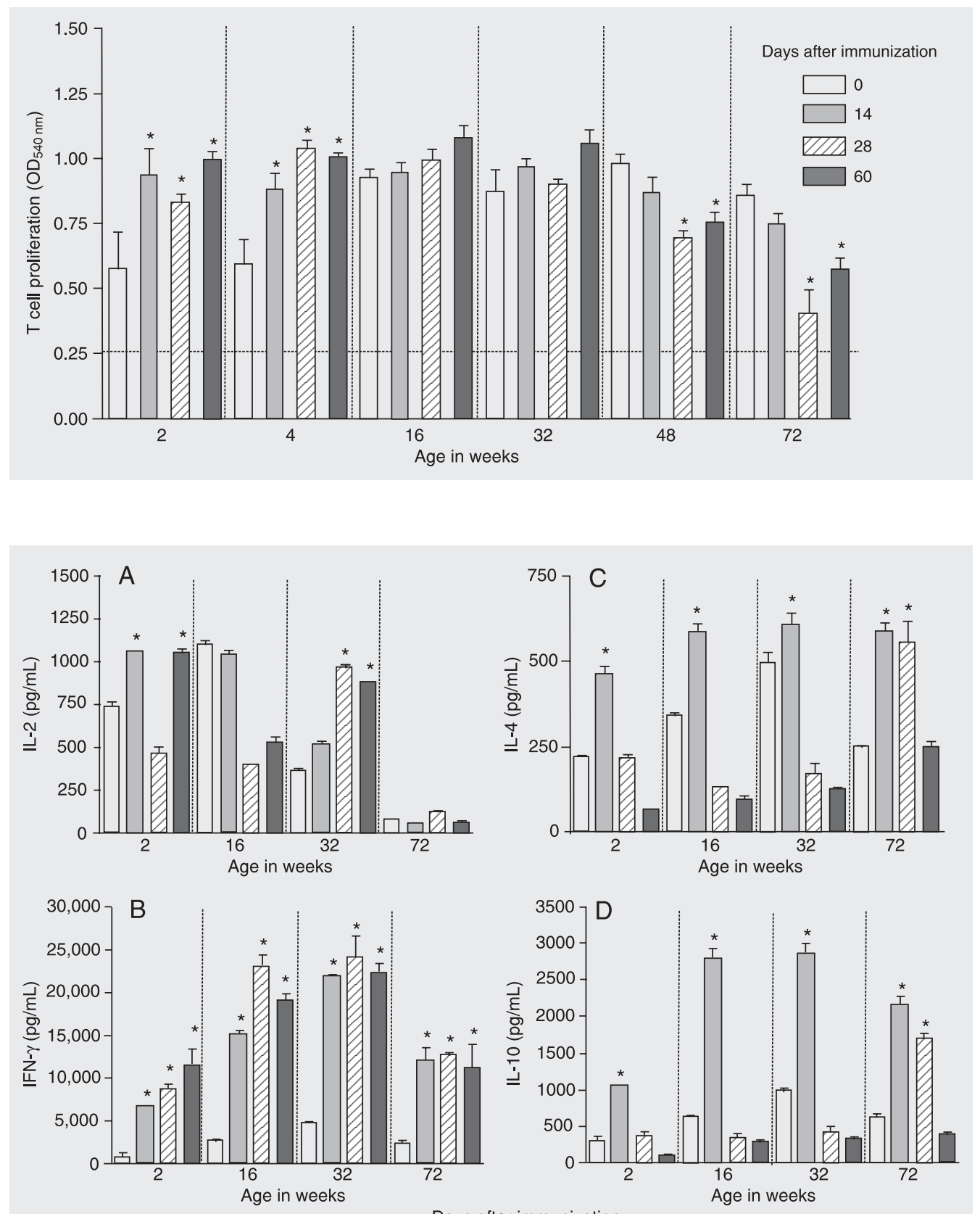

Days after immunization

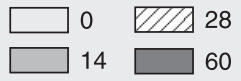


IL-4 and IL-10 levels in the supernatants of spleen cell cultures of naive mice also increased significantly with age up to 32 weeks (Figure 3C,D). The levels of IL-4 and IL-10 in the culture supernatants of cells harvested 14 days after immunization increased significantly over those obtained in the supernatants of naive cells for all ages (Figure 3C,D). IL-4 and IL-10 levels did not increase in the supernatants of spleen cells collected 28 days after immunization compared to those detected in the supernatants of naive cells, except in the oldest group, in which these levels were sustained. No significant difference was observed in the su- pernatants of spleen cells collected 60 days after immunization.

\section{T cell population profiles}

To determine putative age-related alterations in T cell frequency, the spleen cells of naive $\mathrm{BALB} / \mathrm{c}$ mice aged 2 to 96 weeks were examined by flow cytometry using double staining with anti-CD3 and anti-CD4 or antiCD8 antibodies; the results are shown in Figure 4. The percentage of $\mathrm{CD} 4^{+}$and $\mathrm{CD} 8^{+}$ $\mathrm{T}$ cells increased significantly up to eight weeks of age (7.28-25.88\% for $\mathrm{CD}^{+}$; 3.38 $14.88 \%$ for $\left.\mathrm{CD}^{+}\right)$, remaining unchanged

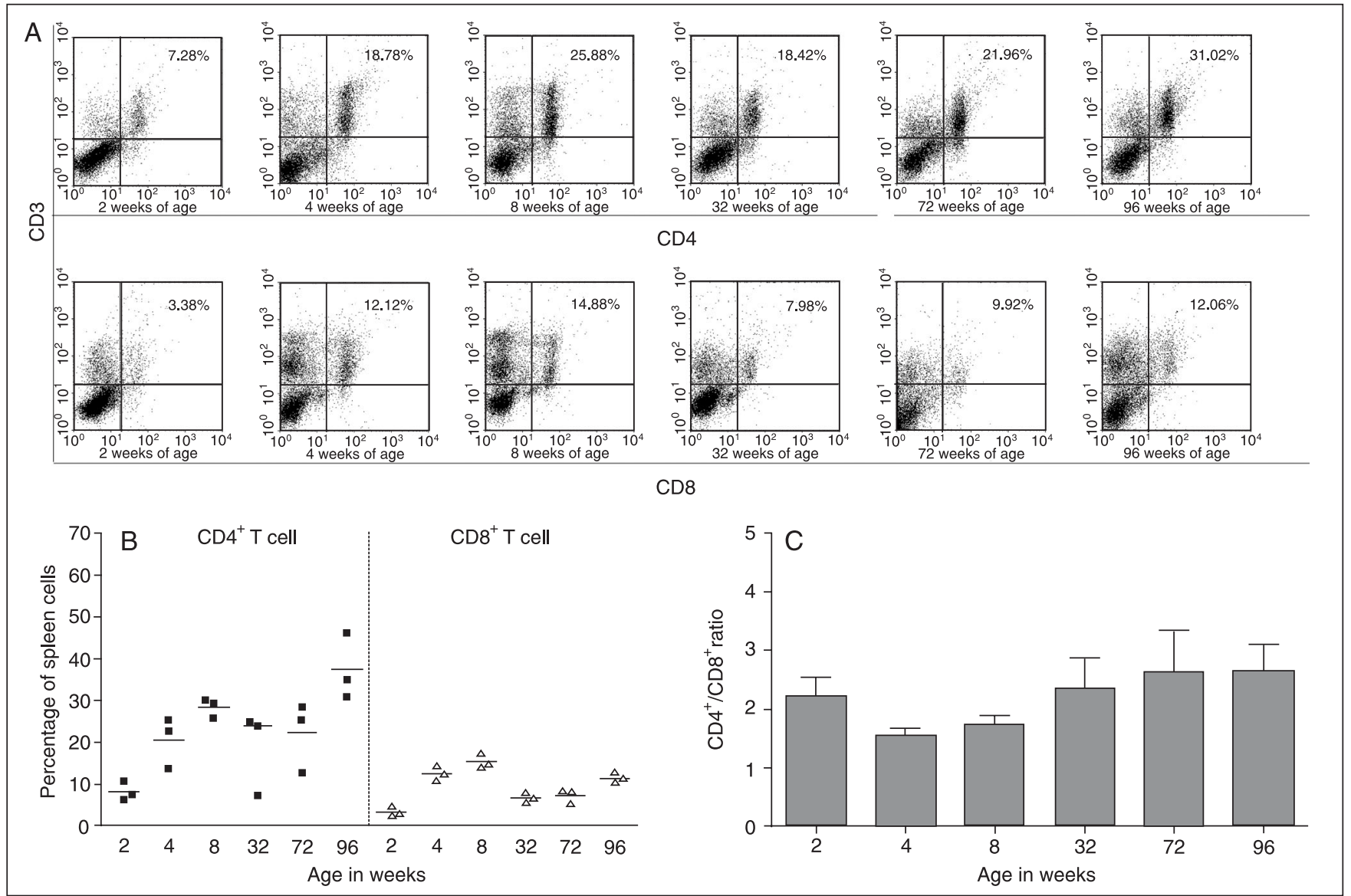

Figure 4. Age-related changes in T cell profile. Cells were collected from spleen of naive BALB/c mice at various ages, and labeled with anti-CD3, antiCD4 and anti-CD8 antibodies. Panel A, Representative example of cytofluorimetric analysis (the numbers inside the plots indicate the mean percentages of double-positive T cells). Panel B, Data are reported as median of individual percentages of spleen cells expressing $\mathrm{CD}^{+} \mathrm{CD} 4^{+}$or $\mathrm{CD}^{+} \mathrm{CD}^{+}$. Panel $C, \mathrm{CD} 4 / \mathrm{CD} 8 \mathrm{~T}$ cell percentage ratios. The assays were carried out in triplicate and data are representative of three separate experiments. 
thereafter. No significant changes in $\mathrm{CD}^{+} /$ $\mathrm{CD} 8^{+}$ratio were observed with aging.

\section{Discussion}

The aging process affects both the humoral and cell-mediated immune responses, a situation that has been blamed for the high incidence of infectious and tumoral illnesses in older individuals. It has been shown that aging provokes changes in the capacity to mount a primary immune response, with older individuals being less responsive to the antigens used for primary immunization $(8,10,11,30)$, although the secondary response is thought not to undergo a significant change with age (11).

Most of the research on age-related alterations in the immune system has investigated the process at specific times during the lifetime, with subjects being arbitrarily defined as young or old. The absence of criteria for the definition of age groups may, thus, be one cause of the conflicting interpretations. Some reports have suggested that senescence marker protein-30 can be used as a specific marker for aging (31-33). This protein, expressed by hepatocytes, pulmonary and renal cells in rats and mice, gradually decreases with age $(33,34)$.

In the present study, we used the age groups defined by these investigators for the analysis of the immune response, i.e., newborn mice (up to 2 weeks of age), young mice (up to 6 weeks of age), adult mice (up to 24 weeks of age), middle-aged mice (up to 48 weeks of age), old mice (up to 72 weeks of age), and very old mice (96 weeks of age). Antibody production up to one year after immunization with TNP-BSA was investigated in these groups. The primary responses to TNP or BSA were quite similar in all animals up to 48 weeks of age, although the older mice (72 weeks of age) presented significantly reduced antibody levels to both the haptenic and protein portions of the antigen. Re-challenge with the antigen rapidly elevated the antibody lev- els in all experimental groups. Interestingly, neonate animals ( 2 weeks of age) had intermediate antibody levels compared to those observed in the sera of old and adult animals for both the primary and secondary responses. These results indicate that the immune system of young and old animals displays the same functioning pattern, although at different levels of antibody response, with old mice (72 weeks of age) being less responsive to the antigen after both primary and secondary immunization. These results may reflect a more limited repertoire in the older individuals rather than a reduced response capacity $(14,35,36)$. Alternatively, the lower antibody levels observed in the older mice may reflect alterations in $\mathrm{T}$ cell function, as suggested by several investigators (for reviews, see Refs. 7,37,38).

To test the latter hypothesis, we carried out experiments to determine mitogen-induced $\mathrm{T}$ lymphocyte proliferation in spleen cells from naive and immunized mice of different ages. Confirming our assumptions, age-related changes in mitogen-induced proliferation were observed for the $T$ cells of both naive and immunized mice, with the youngest (2 and 4 weeks) and oldest (48 and 72 weeks) being the least responsive to ConA. Moreover, cells from immunized mice were more responsive to Con-A than cells from naive mice. However, these results seem to be more related to the administration of the adjuvant than to antigen immunization since the mice that received only FCA displayed results similar to those observed in mice that received the antigen plus the adjuvant. Also, we have observed in our laboratory that antigen-specific proliferation does not change significantly with aging in immunized mice (data not shown).

Studies carried out by Cakman et al. (22) showed that dysregulation in $\mathrm{T}$ helper cell subpopulations may contribute to the downregulation of the antibody response, as indicated by the production of low affinity antibodies and auto-antibodies instead of antigen-driven ones in elderly subjects. Here, 
we also observed significant changes in TH1 and $\mathrm{TH} 2$ cytokine levels in the supernatants of Con-A-stimulated spleen cells with advancing age. IL-2 and IFN- $\gamma$, for example, were present at higher concentrations in the supernatants of spleen cells from younger mice (16 and 32 weeks of age). The present data agree with earlier studies describing a decrease in IL-2 production related to aging $(16,28,38)$, although some reports have shown no significant changes or even an increase in IL-2 expression in response to mitogenic stimulation in older humans and rodents (for reviews, see Ref. 7).

Age-related changes in the capacity to respond to mitogens and to produce $\mathrm{TH} 2$ cytokines have also been the subject of controversy in the literature (for reviews, see Refs. 7,15,16). Some investigators have shown an increase in IL-4 levels in mitogenstimulated cells (for reviews, see Refs. 15, $17,19)$ while others have detected a decrease in IL-4 synthesis in mitogen-stimulated spleen cells in aged experimental models (for reviews, see Refs. 15,39). Here, we observed that the levels of IL-4 and IL-10 increased progressively in the supernatant of Con-A-stimulated T cells from naive mice 2 to 32 weeks of age, and were significantly lower than those in the supernatants of spleen cells from older mice. Fourteen days after primary immunization, the levels of these cytokines were significantly increased in the $\mathrm{T}$ cell cultures from all age groups, in contrast to what was observed from non-immunized or boosted mice. Thus, our results showed that $\mathrm{T}$ cells from young mice were more efficient in the production of both TH1 and $\mathrm{TH} 2$ cytokines than were those from older mice. In addition, the TH1 and TH2 cytokine kinetics were distinct since TH1 levels were maintained for long periods of time after immunization, while those of $\mathrm{TH} 2$ cytokines decreased rapidly. However, the oldest mice sustained the production of $\mathrm{TH} 2$ cytokines for a longer period of time after immunization.
Previous reports have shown that agedependent changes in $\mathrm{T}$ cell behavior may be a consequence of thymus involution and consist of a gradual decrease in number of cells, with an increase in the $\mathrm{CD} 4^{+} / \mathrm{CD}^{+}$ ratio due to the relative reduction in the number of $\mathrm{CD}^{+} \mathrm{T}$ cells (24). However, other studies have found a decrease in CD4/ $\mathrm{CD} 8$ ratio in mice as they aged, reflecting a significant decrease on $\mathrm{CD}^{+}{ }^{+} \mathrm{T}$ cell numbers and only a slight decrease in CD8 T cells (20). Studies on human beings have shown that the percentage of $\mathrm{CD}^{+} \mathrm{T}$ cells does not vary throughout their lifetime, although $\mathrm{CD} 8^{+}$ $\mathrm{T}$ cells suffer a decrease in number and density of surface molecules, probably contributing to a reduction in host defenses against viral infections $(24,40)$. Our results partially agree with those reported in the literature, i.e., the percentage of $\mathrm{CD}^{+}{ }^{+} \mathrm{CD}^{+}$ and $\mathrm{CD}^{+}{ }^{+} \mathrm{CD} 8^{+}$cells increased up to 8 weeks of age, and the CD4/CD8 cell ratio did not change significantly with aging.

We consider the aging process to be responsible for changes in the immune system that result in differentiated immune responses in younger and older animals, but this does not necessarily mean that these responses are insufficient for the maintenance of homeostasis in the elderly. However, our results have also shown that the immune system of older individuals is less responsive to new antigens, as shown by the low levels of antibodies generated against exogenous proteins. Perhaps, a limited repertoire of lymphocytes may leave old subjects less prepared to deal with newly encountered infectious agents or altered selfantigens, thus leading to the greater susceptibility of the elderly to infections and cancer.

\section{Acknowledgments}

The authors thank Dr. Fernando de Queiroz Cunha, Universidade de São Paulo, for providing the anti-cytokine hybridomas, and Fernanda Gonçalves Pereira for carrying out the flow cytometer assays. 


\section{References}

1. Fukagawa NK. Aging: is oxidative stress a marker or is it causal? Proc Soc Exp Biol Med 1999; 222: 293-298.

2. Kajstura J, Pertoldi B, Leri A, Beltrami CA, Deptala A, Darzynkiewicz $Z$, et al. Telomere shortening is an in vivo marker of myocyte replication and aging. Am J Pathol 2000; 156: 813-819.

3. Wolf FI, Torsello A, Covacci V, Fasanella S, Montanari M, Boninsegna $A$, et al. Oxidative DNA damage as a marker of aging in WI-38 human fibroblasts. Exp Gerontol 2002; 37: 647-656.

4. Lang CA, Mills BJ, Lang HL, Liu MC, Usui WM, Richie J Jr, et al. High blood glutathione levels accompany excellent physical and mental health in women ages 60 to 103 years. J Lab Clin Med 2002; 140: $413-417$

5. Kishimoto $\mathrm{S}$, Takahama $\mathrm{T}$, Mizumachi $\mathrm{H}$. In vitro immune response to the 2,4,6-trinitrophenyl determinant in aged C57BL/6J mice: changes in the humoral immune response to, avidity for the TNP determinant and responsiveness to LPS effect with aging. $J$ Immunol 1976; 116: 294-300.

6. Makinodan T, Yunis E. Immunology and ageing. In: Good R, Day S (Editors), Comprehensive immunology. New York: Plenum Publishing Corporation; 1977. p 1-70.

7. Pahlavani MA, Richardson A. The effect of age on the expression of interleukin-2. Mech Ageing Dev 1996; 89: 125-154.

8. Doria G, D’Agostaro G, Poretti A. Age-dependent variations of antibody avidity. Immunology 1978; 35: 601-611.

9. Naor D, Bonavida B, Walford RL. Autoimmunity and aging: the agerelated response of mice of a long-lived strain to trinitrophenylated syngeneic mouse red blood cells. J Immunol 1976; 117: 2204-2208.

10. Callard RE, Basten A, Waters LK. Immune function in aged mice. II. B-cell function. Cell Immunol 1977; 31: 26-36.

11. Callard RE, Basten A. Immune function in aged mice. IV. Loss of T cell and $B$ cell function in thymus-dependent antibody responses. Eur J Immunol 1978; 8: 552-558.

12. Borghesi $\mathrm{C}$, Nicoletti C. In vivo and in vitro study of the primary and secondary antibody response to a bacterial antigen in aged mice. Int $J$ Exp Pathol 1995; 76: 419-424.

13. Lu YF, Cerny J. Repertoire of antibody response in bone marrow and the memory response are differentially affected in aging mice. $J$ Immunol 2002; 169: 4920-4927.

14. Viale AC, Chies JA, Huetz F, Malenchere E, Weksler M, Freitas AA, et al. VH-gene family dominance in ageing mice. Scand $\mathrm{J}$ Immunol 1994; 39: 184-188.

15. Chakravarti B, Abraham GN. Aging and T-cell-mediated immunity. Mech Ageing Dev 1999; 108: 183-206.

16. Albright JW, Albright JF. Ageing alters the competence of the immune system to control parasitic infection. Immunol Lett 1994; 40: 279-285.

17. Witkowski JM, Li SP, Gorgas G, Miller RA. Extrusion of the $P$ glycoprotein substrate rhodamine-123 distinguishes CD4 memory T cell subsets that differ in IL-2-driven IL-4 production. J Immunol 1994; 153: 658-665.

18. Albright JW, Zuniga-Pflucker JC, Albright JF. Transcriptional control of IL-2 and IL-4 in T cells of young and old mice. Cell Immunol 1995; 164: 170-175.

19. Aoki K, Asano K, Okamoto K, Yoshida T, Kuroiwa Y. Age-related changes in ConA-induced cytokine production by splenocytes from senescence accelerated mice SAMP8. Immunol Lett 1995; 46: 169-175.

20. Callahan JE, Kappler JW, Marrack P. Unexpected expansions of CD8-bearing cells in old mice. J Immunol 1993; 151: 6657-6669.

21. Doria G, Frasca D. Ageing and genetic control of immune responsiveness. Immunol Lett 1994; 40: 231-233.
22. Cakman I, Rohwer J, Schutz RM, Kirchner H, Rink L. Dysregulation between TH1 and TH2 T cell subpopulations in the elderly. Mech Ageing Dev 1996; 87: 197-209.

23. Wakikawa A, Utsuyama M, Hirokawa K. Altered expression of various receptors on $\mathrm{T}$ cells in young and old mice after mitogenic stimulation: a flow cytometric analysis. Mech Ageing Dev 1997; 94: 113-122.

24. Banerjee M, Sanderson JD, Spencer J, Dunn-Walters DK. Immunohistochemical analysis of ageing human B and $\mathrm{T}$ cell populations reveals an age-related decline of CD8 T cells in spleen but not gutassociated lymphoid tissue (GALT). Mech Ageing Dev 2000; 115: 85-99.

25. Sun $\mathrm{Y}$, Li H, Langnas AN, Zhao $\mathrm{Y}$. Altered allogeneic immune responses in middle-aged mice. Cell Mol Immunol 2004; 1: 440-446.

26. Rittenberg MB, Amkraut AA. Immunogenicity of trinitrophenylhemocyanin: production of primary and secondary anti-hapten precipitins. J Immunol 1966; 97: 421-430.

27. Little JR, Eisen HN. Preparation and characterization of antibodies specific for the 2,4,6-trinitrophenyl group. Biochemistry 1966; 5: 3385-3395.

28. Simioni PU, Fernandes LG, Gabriel DL, Tamashiro WM. Induction of systemic tolerance in normal but not in transgenic mice through continuous feeding of ovalbumin. Scand J Immunol 2004; 60: 257266.

29. Leo P, Ucelli P, Augusto EF, Oliveira MS, Tamashiro WM. Anti-TNP monoclonal antibodies as reagents for enzyme immunoassay (ELISA). Hybridoma 2000; 19: 473-479.

30. Pawelec G. Immunosenescence and vaccination. Immun Ageing 2005; 2: 16.

31. Fujita T, Uchida K, Maruyama N. Purification of senescence marker protein-30 (SMP30) and its androgen-independent decrease with age in the rat liver. Biochim Biophys Acta 1992; 1116: 122-128.

32. Fujita T. Senescence marker protein-30 (SMP30): structure and biological function. Biochem Biophys Res Commun 1999; 254: 1-4.

33. Mori T, Ishigami A, Seyama K, Onai R, Kubo S, Shimizu K, et al. Senescence marker protein-30 knockout mouse as a novel murine model of senile lung. Pathol Int 2004; 54: 167-173.

34. Jung KJ, Ishigami A, Maruyama N, Takahashi R, Goto S, Yu BP, et al. Modulation of gene expression of SMP-30 by LPS and calorie restriction during aging process. Exp Gerontol 2004; 39: 1169-1177.

35. Modigliani Y, Coutinho G, Burlen-Defranoux O, Coutinho A, Bandeira A. Differential contribution of thymic outputs and peripheral expansion in the development of peripheral T cell pools. Eur $\mathrm{J}$ Immunol 1994; 24: 1223-1227.

36. de Faria AM, Ficker SM, Speziali E, Menezes JS, Stransky B, Silva Rodrigues $\mathrm{V}$, et al. Aging affects oral tolerance induction but not its maintenance in mice. Mech Ageing Dev 1998; 102: 67-80.

37. Goonewardene IM, Murasko DM. Age-associated changes in mitogen-induced lymphoproliferation and lymphokine production in the long-lived brown-Norway rat: effect of caloric restriction. Mech Ageing Dev 1995; 83: 103-116.

38. Frasca D, Pucci S, Goso C, Barattini P, Barile S, Pioli C, et al. Regulation of cytokine production in aging: use of recombinant cytokines to upregulate mitogen-stimulated spleen cells. Mech Ageing Dev 1997; 93: 157-169.

39. Kirman I, Zhao K, Tschepen I, Szabo P, Richter G, Nguyen H, et al. Treatment of old mice with IL-2 corrects dysregulated IL-2 and IL-4 production. Int Immunol 1996; 8: 1009-1015.

40. Ruiz M, Esparza B, Perez C, Barranquero M, Sabino E, Merino F. CD8+ T cell subsets in aging. Immunol Invest 1995; 24: 891-895. 